\title{
Location-allocation of traffic police patrols in the suburban
}

\section{network}

\author{
Beheshteh Moghadas poor ${ }^{1}$, Fatemeh Sabouhi ${ }^{2}$, Ali Bozorgi-Amiri ${ }^{3 *}$, Mohammad Saeed \\ Jabalameli $^{4}$
}

\begin{abstract}
Nowadays, due to population increase and expansion of the transportation networks, the monitoring of this network, control, and prevention of accidents and crimes are very important. The main tasks of traffic patrols, like other emergency-security facilities, are the monitoring and prevention of crime as well as handling and fining in the case of committing crimes. Traffic patrols should be present in the scene and also in high traffic congestion, to reduce accidents and crimes. This paper presents a bi-objective and stochastic optimization model to design an emergency-security system. This network includes traffic patrol vehicles and manpower in patrol vehicles. The objective of the proposed model is to maximize the number of vehicles passing through patrols and minimize the costs according to different scenarios. To solve the model, the epsilonconstraint method is used which simultaneously determines the location of the patrols, allocation of demand points to patrols, and determining the number of existing manpower in patrols. To evaluate and analyze the proposed model, a numerical example is used.
\end{abstract}

Keywords: Location-allocation, Police, Traffic police patrols, Traffic fines, Suburban road networks, Stochastic programming

Manuscript was received on 01/02/2019, revised on 08/08/2019 and accepted for publication on 28/09/2019.

\section{Introduction}

In recent years, due to the increased availability of vehicles and traffic volume, driving offences and accidents have increased significantly. Tian Wang et al. [46] used algorithms and various theories such as graph theory to show the loss and damage caused by traffic and real constraints in practice are so significant. As a result, the need for direct presence of traffic police in road networks is essential to maintain security, especially in the suburban road networks which have a lot of accidents and crimes. However, it is difficult to measure the level of road and street safety [5].

Beenstock and Gafni [3] found that accidents range depends on a variety of factors, such as road quality, police monitoring, and the number of retreated vehicles on the road. Yu Niu He et al. [25] believed traffic congestion in different roads is related to the flow of traffic and how traffic police patrol cars are allocated. For example, the law enforcement plan in Australia and New Zealand,

\footnotetext{
1 School of Industrial Engineering, Iran University of Science and Technology, Tehran, Iran, Email: b_moghadas95@ind.iust.ac.ir

${ }^{2}$ School of Industrial Engineering, Iran University of Science and Technology, Tehran, Iran, Email: sabouhi@ind.iust.ac.ir

${ }^{3}$ School of Industrial Engineering, College of Engineering, University of Tehran, Tehran, Iran, Email: alibozorgi@ut.ac.ir

4 School of Industrial Engineering, Iran University of Science and Technology, Tehran, Iran, Email: jabal@iust.ac.ir
} 
which located the police forces in roads randomly, has resulted in a significant reduction in traffic accidents and crimes [37].

In studies on accident prevention, the police force is considered as one of the most important security factors in reducing crimes and accidents on the roads [9,13,19]. Observation and monitoring of police cause drivers to commit crimes and to deal with accidents more rapidly, which leads to prevention of heavy traffic due to accidents. The main objective of police forces is to increase road safety, which is possible by controlling and dealing with drivers and preventing crimes and faults resulting in accidents and injuries [20,11]. Organization for Economic Cooperation and Development (OECD) [38] defined traffic police regulations as "field of activities performed to control the drivers' behavior through prevention, rewarding, and punishment to obtain security.

The field of work of traffic police is classified into two aspects: prevention and law enforcement. Prevention of traffic crimes is carried out by increasing drivers' awareness of potential dangers in driving regarding the different location and time [20,21]. Though the law enforcement aspect also called the repression aspect, includes times and locations where most of the traffic crimes happen. This aspect attempts to influence the drivers' minds for fear of getting caught and thus prevent to commit crimes and be fined $[49,32]$.

The above-mentioned aspects are possible using different facilities such as police patrols, control cameras, etc. For example, Paolo et al. [12] presented a model to select the best location for installing control and security cameras in urban traffic networks to minimize accidents and maximize the control of roads.

Today, police patrols are considered as one of the most well-known activities to carry out the law and preventive policies against crime [41]. These patrols offer emergency services to public safety and potential accidents. A police patrol is a unit of police force established primarily to monitor and implement traffic safety on roads and highways. There are many management difficulties for the settings, deployment, and scheduling of police patrols to respond to potential accidents. This is generally approved by all countries that the monitoring and law enforcement of the police forces should be carried out based on accident analysis and the use of scientific methods $[23,40]$.

To this end, the police patrol problem has been modeled, analyzed, and investigated in various studies according to the two-mentioned aspects. One of the important aspects of police forces investigation is the investigation of dispatching time and arriving at the scene on time.

Zhao et al. [54] developed a model to minimize the maximum arriving time of patrols by considering a specific traffic volume. kou et al. [30] presented a model to minimize the dispatching time and reviewed the dispatching time between the two sites with and without concerning sensitive points. Zhao et al. [55] developed a model to help the police arrive as early as possible, and solved the model using particle swarm optimization algorithm. keskin et al. [29] presented a bi-objective problem to design the schedule of sending police patrols. The objectives of the problem included: 1 . Minimizing the variable workload between patrols dispatching. 2. Minimizing response time to the calls to demand services. He et al. [24], examined the problem of police force allocation and minimize time to eliminate traffic congestion.

Some studies have employed different simulation methods such as Monte Carlo to better investigate the existing models for the police force and to achieve the best result. Wu et al. [52] focused on the development of patrol designs and presented a bi-objective optimization model to 
design these models, which minimizes vulnerability and cost. Moreover, they used Monte Carlo simulation algorithm to provide a Pareto optimal solution.

According to $\mathrm{Wu}$ et al. [51], 8 appropriate patterns for police patrols are simulated using the input data from Monte Carlo theory considering that the accidents are happening randomly. They believe that the simulation technique is very effective for exploring the patrol patterns and finally concluded that the moving patrols perform much better in response times, working hours, etc. than police stations. In addition to dispatching time of police patrol and timely investigation of accidents and crimes, it is important to investigate the location of police patrol in urban and suburban networks.

Optimal location-allocation is important in two aspects of the private sector (locating factories, warehouses, stores, and allocation of customers, etc.) and the public sector (locating schools, waste collection centers, etc.).

Location-allocation problems are investigated in the private sector to maximize the cost-benefit, but in the public sector the objective is to maximize social benefits. In location-allocation problems, there has already been a serious focus on locating of the emergency-relief vehicles $[15,16,17,22,31,43,50]$.

To determine the best location to deploy traffic patrols, Meng et al. [36] presented the biobjective programming model using graph theory to determine the location of traffic patrols. As a result, the patrols are regularly organized to get to the site faster. Liu et al. [34] used the genetic algorithm to obtain the best place for police patrol stations and then with the combination of genetic algorithm and graph theory, the model has been developed to allocate traffic patrols. Hussein AlHarthei et al. [1] presented a new approach based on the combination of advanced technologies such as artificial intelligence and Geographical information system that can be used to develop, implement, and testing of police patrols allocation in different locations. Li et al. [33] defined a measure of how much the development of traffic patrols are appropriate. Moreover, the optimization model has been formulated to choose the best location of traffic patrols between candidate points using the Lagrangian relaxation method.

Yang et al. [53] and Camacho et al. [8] provided the best location of police patrols by considering three scenarios related to patrols such as warning mission, traffic jams in main and subsidiary roads according to various criteria such as environment, risk, congestion, etc. Azimi et al. [2] presented a routing model with the probabilistic approach to improve the efficiency of traffic police patrols using graph theory and mathematical algorithms. Moreover, they employed the ant colony algorithm to solve the model. In this model, after identifying the patrol routes, a proper number of patrols can be obtained. Cheung et al. [12] proposed a model for locating of police facilities under budget constraints. The purpose of this model is to minimize the distance and maximize the covering of accident-prone locations by the police patrol. The model reduced the distance between the police stations and the crime centers by $19 \%$ and increased the coverage area by $8 \%$. Su et al. [45] presented a two-stage optimization model based on the need of modern societies to police patrols. First, they discuss the issue of allocating patrols to the roads and then the coverage issue for more prior locations.

The result of studies in the field of police patrol concerning different considerations including speed control of drivers by camera or police force, use of tangible or intangible police force, and according to the location of crime occurrence, etc. is different [21,7]. In many problems related to the establishment of emergency-relief vehicles, demand "covering" is proposed by considering time constraints [4,42]. Covering issues are divided into two categories: set-covering and maximum 
covering. The complete covering was first proposed by Toregas et al. [48] to measure the minimum facilities to cover the entire demand point. Besides, the maximum covering model was proposed by Church and Revelle [14] to establish several facilities to maximize the covered points.

According to the existing constraints in police resources as well as the lack of need to deploy police patrols in some low-risk roads, the use of the maximum covering model is under more attention. By reviewing previous studies, we concluded that there is not enough attention and concentration on the coverage, especially the maximum coverage, in the field of location-allocation of police patrol.

Moreover, it is necessary to consider the effective factors on police man power and their number as a limited resource [26,47]. So far, many researchers have attempted to employ traffic police patrols in the best form under existing constraints in police resources. For example, Peng et al. [39] reviewed the development of traffic police patrol problem considering whether or not the police force has limited resources. The problem can be divided into two types: 1 . assuming that the police forces are infinite, then it should be tried to cover all demand points using minimum police patrol force, 2. assuming that the police forces are finite and should be tried to cover maximum demand points under. However, the two types of mentioned problems can be modeled using the classical coverage method, including the complete coverage and the maximum cover [29].

Another issue in the field of traffic police patrols which was less considered in the previous studies is the variation of demand or the number of vehicles passing on various roads at various times. In this way, different traffic volumes can be considered for a road at different seasons. For example, some seasons include the vacations of schools and universities or some of them include vacations related to important occasions. As a result, we have different traffic volumes on suburban roads to carry out the trip. For this purpose, a two-stage stochastic programming method can be used to better analyze the data.

According to the study of this field, the research gap is the lack of attention to the maximum covering for police patrols location, the number of human resources in patrols, their wage, lack of consideration to the various patrol vehicle with various maintenance and fuel cost, the direct relation between better monitoring and the number of police forces, and the uncertainties of traffic volumes under time period, which has been investigated in next sections. As a result, the locationallocation problem of the traffic patrol is derived from emergency-relief issues, road security, and assurance of public order. Therefore, it is necessary to propose an optimization model for police patrols in order to reduce traffic crimes, road accidents, and traffic congestion in high-risk and heavy traffic roads to. In this study, it should be tried to find the best location for proper allocation of roads to traffic patrols, and to provide better security and order. The main objective of this paper is to determine the number of existing human resources in each patrol, distinguishing different types of vehicles, considering stochastic programming and different scenarios and considering minimizing the cost in addition to the maximum covering. It is worth noting that most of the studies carried out on the location of police patrols focused on the urban patrols $[35,31,16,10]$. Consequently, in this study, we focus on the suburban roads network.

This paper is organized as follows: in the second section, we discuss the problem and the proposed model, in the third section we examine the method and the results of the solution, and in the fourth section, we examine the Applicability of model with using numerical example. 


\section{The statement of the problem}

As mentioned earlier, finding the best location for traffic patrols and the proper allocation of demand points to patrols, which include roads, can provide maximum order and security in the roads network. The assumptions of the proposed model are as follows:

The proposed model identifies the best location for a limited number of traffic patrols as well as allocation of demand points to patrol vehicles under different scenarios. Given that the number of human resources is limited, the model determines the best number of human resources in any patrol vehicle. with considering traffic or risk of demand points.

In this regard, different vehicles for police patrols including automobiles and motorcycles have been considered in different types, each of which has a specific number of manpower and costs. As mentioned, choosing between automobiles and motorcycles depends on the traffic volume of the covered area and the number of accidents in that area.

Our model is regarded as a multi-period problem that there are a limited number of available patrol vehicles and active human forces to dispatch to the mission, which the model tries to minimize the use of them at the same time using the benefit of police presence. It is essential to note that each of the demand areas may have different geographical conditions, traffic volumes, and accident statistics, the patrol vehicle must be operated according to these conditions. As a result, these different patrol vehicles have different repair, maintenance, and fuel costs. Notably, every manpower receives the wage per hour.

In the proposed model, the decisions taken are as follows :

- Optimal locations for the deployment of police patrols

- Optimal allocation of demand points to police patrols

- The number of police patrol forces deployed in different locations

In fact, in this study, a bi-objective allocation model involves the maximum number of vehicles assigned in a particular location, or the maximum covering problem, which is the maximum benefit from the presence of the police and at the same time the minimum costs resulting from the patrols and the wages of the manpower. The purpose of this model is to determine the decision points mentioned by the scenario.

Decision variables are divided into two categories: Independent variables of scenario and scenario-dependent variables. The decision is taken in two steps: The first step is to determine the first stage variables. This step will determine the appropriate location for the patrols.

in the second step, the values of the second stage variables are determined according to each scenario.

A detailed study on the two-period probabilistic program, its advantages, and its applications were conducted by Birge and Louveaux in 2011 [6].

\section{The proposed mathematical model}

\subsection{Model sets and indexes}

$I \quad$ Set of roads on network $i \in I, j \in I$ 
$i \quad$ Set of roads (demand points)

$j \quad$ Set of potential roads (points) for traffic police patrol

$F \quad$ Set of shifts

$S \quad$ Set of scenarios

$K \quad$ Set of traffic police patrol vehicle type

\subsection{Model parameters}

$d_{i j} \quad$ Shortest Distance from $i$ to $j$ zones

$S_{j} \quad$ maximum acceptable service distance for road $i$

$U^{s} \quad$ number of vehicles per hour passing a traffic police patrol on point $j$ under scenario $s$

$e_{i} \quad$ time handling events on node $i$ in a shift (in hours)

$H_{f} \quad$ The duration of shift $f$

$t_{i j k} \quad$ travel times between $i$ and $j$ and back (in hours)

$N_{i} \quad$ set of road $j$ within acceptable distance of $\operatorname{road} i\left(N_{i}=\left\{j / d_{i j} \leq S_{i}\right\}\right)$

$w_{f} \quad$ The Number of human recourses available traffic police per shift

$m_{f k} \quad$ Maximum Number of police patrol should available on patrol type $k$ in shift $f$

$v_{j k} \quad$ Set-up Cost of traffic police patrol type $k$ on zone $j$

$C_{f} \quad$ The wage of human resource in shift $f$

$p_{s} \quad$ Probability of scenario $s$

$A_{k} \quad$ Maximum Number of human resource in patrol vehicle $k$

\subsection{Model variables}

$X_{j f k} \quad 1$ if traffic police patrol type $\mathrm{k}$ is located at potential point (road) $\mathrm{j}$ in shift $\mathrm{f}$, otherwise 0

$Z_{i j f}^{s} \quad 1$ if zone(road) $\mathrm{i}$ is covered by traffic police patrol on point (road) $\mathrm{j}$ under scenario $\mathrm{s}$ in

$Q^{s}{ }_{j f k} \quad$ Number of human resource in patrol vehicle k at point (road) $\mathrm{j}$ under scenario s in shift $\mathrm{f}$

\subsection{The proposed mathematical model}

Objective function

$\operatorname{Max} \sum_{s} p_{s} \cdot\left(\sum_{k} \sum_{j} \sum_{f}\left(H_{f} \cdot U^{s}{ }_{j} \cdot X_{j f k}-\sum_{i}\left(t_{i j k}+e_{i}\right) \cdot U^{s}{ }_{j} \cdot Z^{s}{ }_{i j f}\right)+\sum_{k} \sum_{j} \sum_{f} Q^{s}{ }_{j k k} \cdot U^{s}{ }_{j} \cdot H_{f}\right)$ 


$$
\operatorname{Min} \sum_{s} p_{s} \cdot\left(\sum_{k} \sum_{j} \sum_{f}\left[v_{j k} \cdot X_{j f k}+C \cdot\left(H_{f} \cdot Q_{j f k}^{s}\right)\right]\right)
$$

In the first part of the maximization objective function (Eq. 1), the objective is to maximize the number of passing vehicles facing patrol $k$ located at the location $j$, considering that when the patrol leaves the location $j$, it does not detect a fraction of the vehicles passing through $j$ till it returns to this location. This fraction consists of dispatching time, accident management, and return to location $j$.

The second part of the first objective function tries to maximize the number of active human force in the patrol $k$ in the location $j$ proportional to the importance and the amount of vehicle flow through that location.

The second objective function minimizes the cost due to the activation of patrol $k$ proportional to location $\mathrm{j}$ as well as manpower wage.

\subsection{Constraints}

$$
\begin{array}{cc}
\sum_{j} x_{j f k} \leq m_{f k} & \forall f, k \\
\sum_{j} Z_{i j f}^{s}=1 & \forall i \in I, f \in F, s \\
Z_{i j f}^{s} \leq \sum_{k} X_{j f k} & \forall i \in I, j \in J, f \in F, s \\
\sum_{f} \sum_{k} X_{j f k} \leq 1 & \forall j \in J \\
\sum_{j, k} Q_{j f k}^{s} \leq w_{f} & \forall f \in F, s \\
Q_{j j k}^{s} \leq A_{k} . X_{j f k} & \forall j \in J, f \in f, k, s \\
Q^{s}{ }_{j f k} \geq X_{j f k} & \forall j \in J, f \in f, k, s \\
\sum_{k} X_{j f k} \leq 1 & \forall j \in J, f, s \\
X_{j f k} \in\{0,1\}, & \\
Z_{i j f}^{s} \in\{0,1\}, & \forall j \in J, f \in F, i \in I, k \in K, s \in S \\
Q_{j f k}^{s} \geq 0 &
\end{array}
$$

In Eq. (3) it is emphasized that at each shift, the maximum $\mathrm{m}$ of patrol $\mathrm{k}$ needs to be deployed. In constraint (4), it is noted that each existing road should be covered exactly by a patrol. In constraint (5), it is supposed that if there is no active patrol in location $\mathrm{j}$, it is not possible to cover the road. The constraint (6) is a strong constraint that emphasizes The constraint (6) is a strong constraint that emphasizes if a patrol is in the location $\mathrm{j}$ for a shift, it can no longer be placed in that location in another shift. In constraint (7), the number of manpower invested in every shift in all of the active locations $\mathrm{j}$ must be less than the total number of available manpower per shift. In constraint (8) and 
(9), we have discussed that in each patrol vehicle, at least one force and the maximum number of force (according to the corresponding parameters) can be present. In constraint (10), it is guaranteed that in each shift only one type of patrol vehicle can be activated in place j. Finally, in constraint (11), positive and binary variables are determined.

\section{Solution procedure}

In multi-objective problems with conflicting functions, it is impossible to find the solution to optimize all of the functions simultaneously. In such problems, the focus is on pareto solutions. In other words, the solutions that improve none of the functions without having at least one of the functions become worse. There are different methods for solving multi-objective optimization models such as weighting method, goal programming method, etc. but for different reasons these methods are not efficient like lack of access to the weight that is determined by the decision-makers $[27,28]$.

In this paper, the epsilon-constraint method is used to solve the model. The epsilon-constraint method is employed to solve multi-objective problems. In this method, all objective functions except one are converted to the constraint and by changing the epsilon values of the corresponding constraints to the objective functions, a set of Pareto optimal solutions are obtained (Steuer et al.[44]). In this paper, the first objective function is considered as a priority.

\section{Solution result}

To verify the proposed model in the Section 2, we try to implement a numerical example on it and then examine the results to ensure the precision of the model.

In this numerical example, five candidate points for traffic patrols locations, two 12-hours shift, and two types of vehicles (motorcycle and automobile) is considered. To close the model to reality, we investigate the model under four scenarios so that the traffic volume and the number of vehicles passing on different seasons are considered different due to the occasions, holidays, and suburban trips. summer has the heaviest traffic while this volume is decreasing in spring, autumn, and winter respectively.

Then, the proposed model is solved using the epsilon-constraint method using GAMS software. All experiments were carried out using a laptop with Intel Core i7 CPU, $2.5 \mathrm{GHz}$, and $4 \mathrm{~GB}$ of RAM. The solution results are as follows:

Table 1. Established traffic police patrol

\begin{tabular}{ccc}
\hline Second shift & First shift & \\
\cline { 1 - 2 } 2,5 & 1,3 & zones(j) \\
\hline
\end{tabular}

Table 2. The number of man powers is available in patrol

\begin{tabular}{ccc}
\hline \multicolumn{2}{c}{ The number of Traffic police officer } & \\
\hline Second shift & First shift & scenario \\
\hline 3 & 3 & Scenario $1:$ spring \\
4 & 5 & Scenario $2:$ summer \\
2 & 2 & Scenario $3:$ autumn
\end{tabular}


2

$1 \quad$ Scenario $4:$ winter

According to the results, in the seasons with the high traffic volume such as summer, the number of deployed forces in active sites, is more than the others.

\subsection{The conflict to the objective functions}

Figure 1 presents objectives conflict for different scenarios. In the previous section, we noted that, in the numerical example, the amount of traffic volume in different seasons is considered to be different in a way that summer has the heaviest traffic while this volume is decreasing in spring, autumn, and winter respectively.

As the Figure 1 suggests, the level of covering of passing vehicles by a police patrol during the summer season, which has the highest traffic volume for a certain cost, is minimal due to the increasing number of traffic accidents and crimes. As a result, the number of patrols that can stay at its location and keep more traffic under control decreases. By examining the other values, we realize that we have the lowest covering level in the summer with the highest traffic volume and the highest covering level in the winter with the lowest traffic volume and the number of traffic accidents.

Another result is that by increasing the number of traffic patrols established in the candidate locations, the total cost and the covering level of vehicle passing traffic police patrol increased. This highlights the conflict between objectives.

Another point is the linear process between the amounts of coverage in different scenarios for each cost value. This linear process can help decision makers organizations to predict similar behavior in the future. 


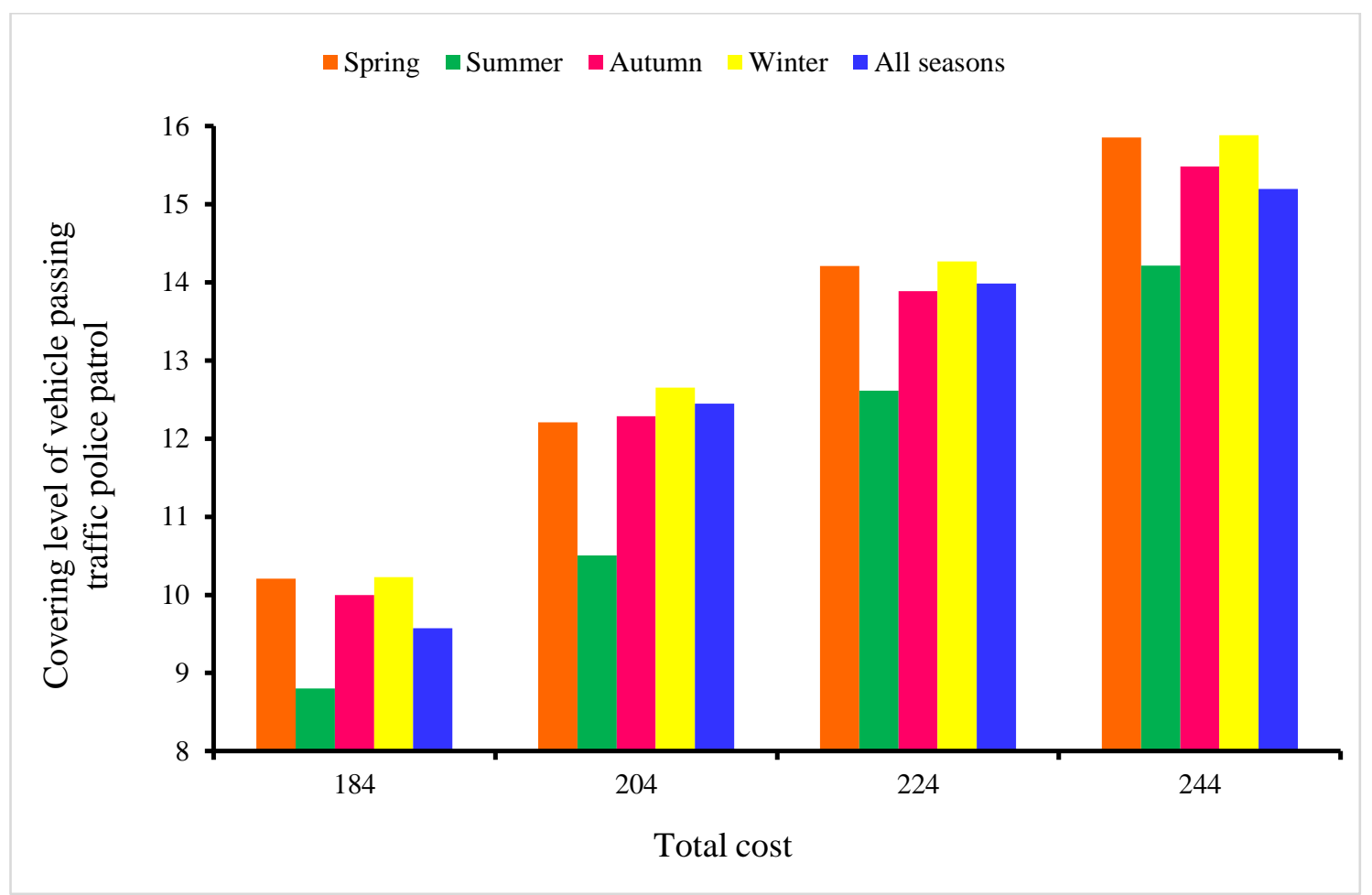

Figure 1. The diagram of contradiction between objective functions

\subsection{Sensitivity analysis on the shift hours}

Besides, to study the behavior and sensitivity of the model to the shift hours, by changing the shift hours, Figure 2 is obtained. As shown in the Figure 2, the Covering level of vehicle passing traffic police patrol is increased by increasing the shift hours. It is evident that if the shift hours increase, the number of vehicles passing the patrol increases.

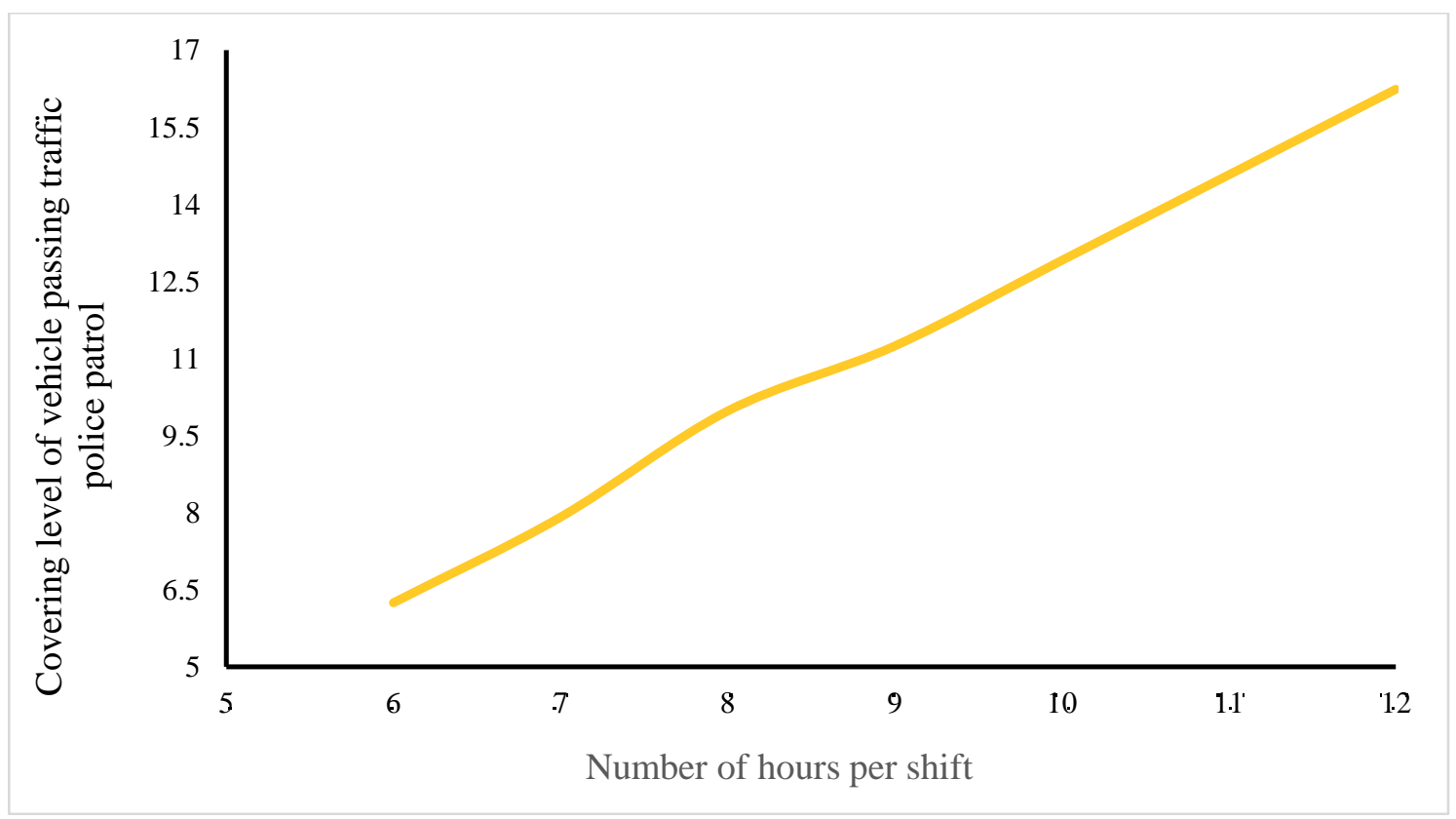


Figure 2. The sensitivity analysis on the shift hours

\section{Conclusion and future research}

In this paper, the location-allocation model of traffic patrols in suburban road networks was proposed. The objective of this study is to maximize the demand cover and the amount of traffic and vehicles crossing the roads and at the same time to minimize the total cost. We introduced different scenarios for vehicle traffic using a two-stage stochastic programming model.

In this paper, a bi-objective stochastic model was proposed for location-allocation of traffic police patrol in the suburban road network. In the proposed model, locating of traffic patrols was considered the first stage decision. while The number of man power available in patrols and allocation of demand points to patrols were the second stage decisions. Moreover, the number of manpower to participate in the patrol is the decision of the second stage. To get closer to reality, capacity constraints, working hours per shift, etc. were considered. To validate the proposed model, a numerical example was considered and the sensitivity analysis was performed and we concluded that there is a conflict between maximum covering and total cost.

The suggestions for future studies are:

- determine the fuel station for police patrol

- determine the location for installing control cameras

\section{References}

[1] Al-Harthei, H., Ben Ali, O., \& Garib, A. (2013). Real-time traffic patrol allocation for Abu Dhabi emirate (UAE). Journal of Traffic and Logistics Engineering, 1(1), 64-68.

[2] Azimi, S. A. Z., \& Bashiri, M. (2016). Modeling Police Patrol Routing and its ProblemSolving Technique Based on the Ant Colony Optimization Algorithm (case Study: Iran's Police). Research Journal of Applied Sciences, 11(7), 536-546.

[3] Beenstock, M., \& Gafni, D. (2000). Globalization in road safety: explaining the downward trend in road accident rates in a single country (Israel). Accident Analysis and Prevention, 32(1), 71-84.

[4] Berman, O., Drezner, Z., \& Krass, D. (2010). Generalized coverage: new developments in covering location models. Computers \& Operations Research, 37, 1675-1687.

[5] Bester, C. J. (2001). Explaining national road fatalities. Accident Analysis and Prevention, 33(5), 663-672.

[6] Birge, J.R., Louveaux, F., (2011). Introduction to Stochastic Programming. Springer.

[7] Bürger, B., \& Nachreiner, F. (2018). Individual and organizational consequences of employee-determined flexibility in shift schedules of police patrols. Police Practice and Research, 19(3), 284-303.

[8] Camacho-Collados, M., Liberatore, F., \& Angulo, J. M. (2015). A multi-criteria police districting problem for the efficient and effective design of patrol sector. European Journal of Operational Research, 246(2), 674-684.

[9] Chang, L. Y., \& Chen, W. C. (2005). Data mining of tree-based models to analyze freeway accident frequency. Journal of Safety Research, 36, 365-375.

[10] Chen, H. (2019). Developing Police Patrol Strategies Based on the Urban Street Network (Doctoral dissertation, UCL (University College London)).

[11] Chen, H., Cheng, T., \& Ye, X. (2019). Designing efficient and balanced police patrol districts on an urban street network. International Journal of Geographical Information 
Science, 33(2), 269-290.

[12] Cheung, C. Y., Yoon, H. T., \& Chow, A. H. (2015). Optimization of police facility deployment with a case study in Greater London Area. Journal of Facilities Management, 13(3), 229-243.

[13] Christensen, P., \& Elvik, R. (2007). Effects on accidents of periodic motor vehicle inspection in Norway. Accident Analysis and Prevention, 39, 47-52.

[14] Church, R., \& Revelle, C. (1974). The maximal covering location problem. Papers in Regional Science, 32,101-118.

[15] Church, R., Sorensen, P., \& Corrigan, W. (2001). Manpower deployment in emergency services. Fire Technology,37, 219-234.

[16] Curtin, K. M., Qiu, F., Hayslett-McCall, K., \& Bray, T. M. (2005). Integrating GIS and maximal covering models to determine optimal police patrol areas. In GIS and crime analysis (Chap. XIII).

[17] Daskin, M. S. (1982). Application of an expected covering model to emergency medical service system design. Decision Sciences, 13(3), 416-439.

[18] Daskin, M. S. (2011). Network and discrete location: models, algorithms, and applications. John Wiley \& Sons.

[19] Elvik, R., Vaa, T., Hoye, A., \& Sorensen, M. (2004). Factors contributing to road accidents. Elvik R, Hoye A, Vaa T, Sorensen M. The Handbook of Road Safety Measures. Oxford: Emerald Group Publishing Limited, 29-79.

[20] ETSC (European Transport Safety Council) (May 1999). Police enforcement strategies to reduce traffic casualties in Europe, Brussels.

[21] Fell, J. C., Ferguson, S. A., Williams, A. F., \& Fields, M. (2003). Why are sobriety checkpoints not widely adopted as an enforcement strategy in the United States? Accident Analysis and Prevention, 35(6), 897-902.

[22] Green, L. V., \& Kolesar, P. J. (2004). Improving emergency responsiveness with management science. Management Science, 50(8), 1001-1014.

[23] Hakkert, A. S., Gitelman, V., Cohen, A., Doveh, E., \& Umansky, T. (2001). The evaluation of effects on driver behavior and accidents of concentrated general enforcement on interurban roads in Israel. Accident Analysis and Prevention, 33, 43-63.

[24] He, Y., Liu, Z., Shi, J., Wang, Y., Zhang, J., \& Liu, J. (2015). K-shortest-path-based evacuation routing with police resource allocation in city transportation networks. PloS one, $10(7)$.

[25] He, Y., Wang, Y., Shi, J., \& Liu, Z. (2014, October). An evacuation network flow optimization model for city transportation systems with policemen resource allocation. In Proceedings 2014 International Conference on Informative and Cybernetics for Computational Social Systems (ICCSS) (45-50). IEEE.

[26] Hurley, W. J., Brimberg, J., \& Pavlov, A. (2009). Optimal thresholds for fining speeders for a stationary speed-check operation when the traffic intensity is low. Journal of the Operational Research Society,60, 1154-1159.

[27] Jabbarzadeh, A., Fahimnia, B., \& Sabouhi, F. (2018). Resilient and sustainable supply chain design: sustainability analysis under disruption risks. International Journal of Production Research, 56(17), 5945-5968.

[28] Jabbarzadeh, A., Haughton, M., \& Pourmehdi, F. (2019). A robust optimization model for efficient and green supply chain planning with postponement strategy. International Journal of Production Economics, 214, 266-283.

[29] Keskin, B. B., Li, S. R., Steil, D., \& Spiller, S. (2012). Analysis of an integrated maximum covering and patrol routing problem. Transportation Research Part E: Logistics and Transportation Review, 48(1), 215-232.

[30] Kuo, P. F., Lord, D., \& Walden, T. D. (2013). Using geographical information systems to 
organize police patrol routes effectively by grouping hotspots of crash and crime data. Journal of Transport Geography, 30, 138-148.

[31] Larson, R. C. (1974). A hypercube queuing modeling for facility location and redistricting in urban emergency services. Computers \& Operations Research, 50(1), 135-145.

[32] Leigh, J., Dunnett, S., \& Jackson, L. (2019). Predictive police patrolling to target hotspots and cover response demand. Annals of Operations Research, 283(1-2), 395-410.

[33] Li, J., Li, F., Wu, Y., \& Tang, Y. (2015, November). Optimizing traffic patrol based on generalized maximal covering model. In 2015 Chinese Automation Congress (CAC) (5963). IEEE.

[34] Liu, H. H., Qiao, H. F., Li, N. P., \& Yao, H. B. (2012). Study on Patrol Service Platform Settings and Scheduling Based on Genetic Algorithm. In Applied Mechanics and Materials (Vol. 182,1713-1718). Trans Tech Publications Ltd.

[35] Ma, L. (2003). Integrating GIS and combinatorial optimization to determine police patrol areas. Unpublished Masters thesis, University of Texas at Dallas, Dallas, TX.

[36] Meng, J. X., \& Lu, X. Z. (2013). The Application of Graph Theory Method in the Problem of Traffic Patrol Police Service Platform's Site Selection. In Applied Mechanics and Materials (Vol. 246,723-727). Trans Tech Publications Ltd.

[37] Newstead, S. V., Cameron, M. H., \& Leggett, L. M. W. (2001). The crash reduction effectiveness of a networkwide traffic police deployment system. Accident Analysis and Prevention, 33, 393-406.

[38] OECD (Organisation for Economic Co-operation and Development) (1974). Research on traffic law enforcement.Paris, France.

[39] Peng, H., Qin, Y., \& Yang, Y. (2015, December). Contrastive Analysis of Heuristic Algorithms for Covering Location Model of Traffic Patrol Police Deployment. In 2015 8th International Symposium on Computational Intelligence and Design (ISCID) (Vol. 2,497-500). IEEE.

[40] Ranasinghe, P. (2017). Rethinking the place of crime in police patrol: A re-reading of classic police ethnographies. British Journal of Criminology, 57(4), 867-884.

[41] Reis, D., Melo, A., Coelho, A. L., \& Furtado, V. (2006, May). Towards optimal police patrol routes with genetic algorithms. In International Conference on Intelligence and Security Informatics (485-491). Springer, Berlin, Heidelberg.

[42] ReVelle, C. S., \& Eiselt, H. A. (2005). Location analysis: a synthesis and survey. European Journal of Operational Research, 165, 1-19.

[43] Simpson, N. C., \& Hancock, P. G. (2009). Fifty years of operational research and emergency response. Journal of the Operational Research Society, 60, 126-139.

[44] Steuer, R. E. (1986). Multiple criteria optimization. Theory, computation and applications.

[45] Su, Z., Fu, Y., \& Liu, Y. (2010). A two-level model for police patrol problem with emergency responses. In ICLEM 2010: Logistics For Sustained Economic Development: Infrastructure, Information, Integration (734-740).

[46] Wang, T., Wan, B., Niu, T., \& Li, J. (2015, January). Traffic Patrol Service Platform Scheduling and Containment Optimization Strategyaper. In Proceedings of the 2015 International Conference on Mechanical Engineering and Control Systems (379-382).

[47] Tillyer, R., Engel, R. S., \& Cherkauskas, J. C. (2010). Best practices in vehicle stop data collection and analysis. Policing: An International Journal of Police Strategies \& Management, 33(1), 69-92.

[48] Toregas, C., Swain, R., ReVelle, C., \& Bergman, L. (1971). The location of emergency service facilities. Operations Research, 19, 1363-1373.

[49] Vanlaar, W. (2008). Less is more: the influence of traffic count on drinking and driving behaviour. Accident Analysis and Prevention, 40, 1018-1022. 
[50] Wright, P. D., Liberatore, M. J., \& Nydick, R. L. (2006). A survey of operations research models and applications in homeland security. Interfaces, 36(6), 514-529.

[51] Wu, J. S., \& Lou, T. C. (2010, October). Evaluating freeway police patrol performance by simulation. In 2010 International Conference on Information, Networking and Automation (ICINA) (Vol. 1,V1-104). IEEE.

[52] Wu, W., Shen, L., Ji, X. J., \& Jin, W. (2014). Analysis of freeway service patrol with discrete event-based simulation. Simulation Modelling Practice and Theory, 47, 141-151.

[53] Yang, B., Hu, Z. H., \& Zhou, J. X. (2015). Configuration, deployment, and scheduling models for management and optimization of patrol services. Mathematical Problems in Engineering, 2015.

[54] Zhao, K. Q., Luo, L., \& Xia, Y. M. (2012). The Optimal Dispatch of Traffic and Patrol Police Service Platforms. Journal of Applied Mathematics, 2012.

[55] Zhao, N., \& Li, Z. (2014). Optimize traffic police arrangement in easy congested area based on improved particle swarm optimization. Procedia-Social and Behavioral Sciences, 138, 408-417. 